\title{
Futebol: necessárias rupturas ${ }^{1}$
}

\author{
Soccer: necessary ruptures \\ Fútbol: necesarias rupturas

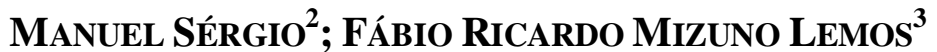 \\ UniversidAde TÉCNICA De LISBOA, UTL, LISBOA, PORTUGAL \\ Instituto Federal de São Paulo, IFSP, São Carlos-SP, Brasil
}

\begin{abstract}
RESUMO
A intenção desse ensaio é apontar reflexões sobre o futebol, em sua possível relação com a motricidade humana, que considera o ser humano no constante movimento intencional da transcendência. Para isso, são sinalizadas algumas rupturas, entre elas: o ser humano que vivencia o desporto não é um ser mecânico, uma máquina, uma dicotomia corpo-mente, sentimentos-consciência, natureza-cultura; seus movimentos não são matematicamente explicados; o mundo não é um relógio. A complexidade humana é afirmada, os sentimentos considerados, para além das táticas e técnicas desportivas. A transformação do futebol é proposta (de mera atividade física à atividade verdadeiramente humana) a partir do desporto escolar e do desporto popular.

Palavras-chave: Futebol. Ruptura. Motricidade Humana.
\end{abstract}

\begin{abstract}
The aim of this essay is to point reflections on soccer and human motricity, which considers the human being in the constant intentional movement of transcendence. For this, some ruptures are signaled, among them: the human being who experiences sport is not a mechanical being, a machine, a dichotomy body-mind, feelingsconsciousness, nature-culture; their movements are not mathematically explained; the world is not a clock. The human complexity is affirmed, the sentiments considered, besides the sports tactics and techniques. The transformation of soccer is proposed (from mere physical activity to truly human activity) from school sports and popular sport.
\end{abstract}

Keywords: Soccer. Rupture. Human Motricity.

\section{RESUMEN}

La intención de este ensayo es apuntar reflexiones sobre el fútbol, en su posible relación con la motricidad humana, que considera al ser humano en el constante movimiento intencional de la trascendencia. Para ello, se señalan algunas rupturas, entre ellas: el ser humano que vivencia el deporte no es un ser mecánico, una máquina, una dicotomía cuerpo-mente, sentimientos-conciencia, naturaleza-cultura; sus movimientos no se explican matemáticamente; el mundo no es un reloj. La complejidad humana es afirmada, los sentimientos considerados, además de las tácticas y técnicas deportivas. La transformación del fútbol es propuesta (de mera actividad física a la actividad verdaderamente humana) a partir del deporte escolar y del deporte popular.

Palabras clave: Fútbol. Ruptura. Motricidad Humana.

\footnotetext{
${ }^{1}$ Versão preliminar publicada em: SÉRGIO, M. A 'ciência' do futebol. A Bola (Portugal), Espaço Universidade-Manuel Sérgio, n. 215, 05 nov. 2017.

${ }^{2}$ Professor aposentado da Faculdade de Motricidade Humana da UTL. E-mail: manuel.sergio.cunha@gmail.com

${ }^{3}$ Professor do IFSP São Carlos. E-mail: fabio.lemos@ifsp.edu.br
} 


\title{
ENSAIO
}

O futebol, como qualquer outra modalidade desportiva é uma das formas da motricidade humana, pois: "A motricidade humana ensina que o ser humano é fundamentalmente relação, no ato (ou no movimento intencional) da transcendência" (SÉRGIO, 2013, p. 78).

\begin{abstract}
A motricidade humana (a energia para o movimento intencional da transcendência, ou da superação), que em actos (ou acções) se corporiza, é inseparável da consciência desta vocação e deste dever. Sem o anseio, visível no corpo em acto, de superação do que se é e do que se tem, não há sujeito. $\mathrm{O}$ ser humano só o é, enquanto acto de superação ou de criação. O ser humano, enquanto ser sem acto é uma alienação (SÉRGIO, 2012, p. 117).
\end{abstract}

Assim sendo, não há como se vislumbrar o futebol, enquanto motricidade humana, a partir de um viés dotado de "desumanidade".

Não há motricidade humana sem sentido, sem vínculo em relação a um objetivo final. Não se pode pois investigar o movimento intencional ao nível exclusivo das propriedades físicas e biomecânicas, pois há nele uma lógica que subsume uma causalidade mais complexa e mais ampla. O movimento intencional é o sintoma de múltiplas ações e variados estímulos (SÉRGIO, 1991, p. 99).

Contudo, desde os inícios do pensamento moderno, mormente com Galileu e Descartes, o "ser humano" e a "ciência" sempre se constituíram como duas realidades estranhas uma à outra: a inteligência, a personalidade, os sentimentos humanos não podiam pesar-se, medir-se, quantificar-se - não eram, com toda a certeza, científicos.

Demais, a ciência moderna nasce e desenvolve-se mecanicista. O universo é uma imensa máquina, composta por um enorme conjunto de máquinas cujas leis importam conhecer. E, por isso, Deus é o divino engenheiro, omnipotente criador de um universo que pode ser estudado, matematicamente.

Não é de estranhar assim que os filósofos e os cientistas de mais ampla inteligência teorizadora tenham comparado o Mundo a um relógio. É o caso de "O homem-máquina" de La Mettrie, filósofo materialista e médico que pretende ensinar que, no mundo todo, só matéria se encontra e é dessa matéria que o ser humano (e tudo) nasce e de que o ser humano é feito. Minucioso e irônico, não abandona o mecanicismo, apontando as leis mecânicas que regem, segundo ele, as funções do corpo de um ser vivo. A saúde depende do funcionamento do corpo, como se de máquina se tratasse (LA METTRIE, 1982).

O mundo é uma grande máquina des-espiritualizada, com leis inalteráveis, que os especialistas dos vários ramos do saber hão-de procurar pesquisar, para manipular as coisas a seu bel-prazer. Galileu [...], Bacon [...] e Descartes [...] iniciam a modernidade, insistindo neste ponto (SÉRGIO, 2012, p. 110111).

A partir desta altura, o sábio deixa de ser o clérigo aristotélico-tomista e passa a ser um leigo, uma pessoa que sabe que não tem a verdade, mas que incessantemente a procura, pela razão e pela reflexão e pelo método experimental. A história das ciências, que vai de Copérnico a Newton é de um progresso admirável e prepara o Iluminismo e informa, claramente, a Revolução Francesa... 
O homem da Sociedade de Informação (o homem hodierno) ainda vive aqui e além deste eterno presente, que são os conceitos básicos do cartesianismo. A ele muito lhe chega fragmentado, dividido, em migalhas: o dualismo sujeitoobjecto, o dualismo corpo-espírito (bem visível no modelo biomédico, o qual analisa a doença em termos reducionistas), a superespecialização que se desvincula de uma visão do todo. Rebelando-se contra delirantes sujeições teológicas e metafísicas; devido ao indiscutível prestígio das ciências, que se inscreve num imperativo respeito pela inteligência humana; [...] o homem ocidental habituou-se a um conhecimento altamente formalizado que imprimiu um carácter distintivo ao seu pensamento e o levou a um certo conformismo intelectual (SÉRGIO, 1999, p. 187).

Não surpreende, portanto, que Ciência, Razão e Progresso caminhassem de mãos dadas e que, quando pela primeira vez, no século XVIII, a expressão Educação Física (que integrava a Ginástica, os Jogos e os Desportos) tenha surgido, no vocabulário científico, os exercícios ginásticos se destinassem ao homem-máquina, a um corpoinstrumento que a Razão esclarecia.

O termo Educação Física aparece, no século XVIII, garbosamente defendido pelo médico suíço Ballesxerd, de acordo com o Michel Foucault da Microfísica do Poder. Segundo o Jacques Ulmann (de la Gymnastique aux Sports Modernes) é em John Locke, um racionalista-empirista, que o termo aparece, pela primeira vez, precisamente no seu livro Alguns pensamentos sobre a educação. Num ponto havemos de convir: A Educação Física é um produto do racionalismo cartesiano e destinava-se ao que, no ser humano, é puramente material e mecânico e portanto só analisável, matemática e experimentalmente (SÉRGIO, 2012, p. 75).

Vale a pena reler a Proposta de Lei, de 25 de fevereiro de 1939, apresentada à Assembleia Nacional para a criação do Instituto Nacional de Educação Física (INEF) português, onde assim se define a Educação Física:

[...] é uma acção intencional que o homem, devidamente dirigido, exerce sobre si mesmo, pela prática racional, sistemática dos exercícios físicos ginástica, jogos, desportos - metódica e conscientemente executados, como complemento essencial dos restantes meios educativos e higiénicos e tendo como objectivos imediatos a saúde, beleza, força, resistência, disciplina, prontidão, espírito de solidariedade, optimismo, confiança em si, domínio de si próprio, coragem, prudência, caráter, personalidade, tornando o corpo o digno instrumento de uma vontade esclarecida (PORTUGAL, 1972).

Como se vê, uma antropagogia, ou teoria da formação do ser humano, assente no corpo-instrumento e apontando para uma antropologia declaradamente dualista. Enfim, a dicotomia corpo-mente, sentimentos-consciência, natureza-cultura emergia da educação física até meados do século XX.

Muita gente que pontifica, no desporto nacional e internacional, ainda não ultrapassou, nem o mecanicismo cartesiano, nem o solo epistemológico do positivismo. No futebol, há muita gente que pensa que sabe explicar o futebol, sem nunca o ter compreendido. Compreendido? Sim, porque ao nível do humano nada escapa à ordem dos valores e das significações, mesmo como exigência do rigor metodológico.

Qual é então a tese a adiantar, na construção de uma teoria crítica do Desporto? Em poucas palavras, podemos assim condensá-la: o Desporto deve 
analisar-se como um processo e uma prática sociais e, por isso, o Ter e o Poder nele se inscrevem no discurso e nas atitudes dos agentes esportivos (SÉRGIO, 1999, p. 255).

Aos "agentes do futebol" seria aconselhável um corte epistemológico, em relação à pré-ciência de um senso comum que analisa o futebol, sem descontinuidade, nos problemas e na linguagem.

O curso de um conhecimento verdadeiramente científico não é linear, o seu grande objetivo é respeitar o Passado, mas construir o Futuro, o que implica pôr de lado e rejeitar muito do que a tradição nos oferece.

A exigência de objetividade, no sentido de objetivação, leva-nos necessariamente a descartar o caráter meramente acumulativo e continuista do saber, bem como a fazer da ideia de progresso descontínuo a espinha dorsal de toda a cientificidade. Se é assim, também esse progresso precisa ser pensado em termos de ruptura (JAPIASSU, 1978, p. 145).

Ruptura, em primeiro lugar com uma organização apressada e desleixada dos clubes. Há dirigentes desportivos de exemplar amor pelos seus clubes, mas sem especialização bastante para, atualmente, organizarem um clube com alta competição, ou alto rendimento. Já é clássica a definição de Drucker (2003):

Uma organização é um grupo humano composto por especialistas que trabalham numa tarefa comum [...] Uma organização é sempre especializada. Define-se pelas suas tarefas [...] Uma organização só é eficaz, se se concentrar numa tarefa. Uma orquestra sinfónica não tenta curar doentes, toca música. Um hospital cuida dos doentes, mas não procura tocar Beethoven [...] A sociedade, a comunidade e a família são; as organizações fazem (p. 61-62).

E, para as organizações fazerem, é imprescindível o contributo de direções competentes.

Donde, logicamente se conclui que organizar é tornar produtivos os conhecimentos. Mas, no âmbito das ciências humanas, um especialista é tanto mais eficaz quanto mais tiver em conta a complexidade humana, presente em todos os elementos que a constituem.

[...] o treinador de futebol de nossos dias deva distinguir-se pelo estudo pertinaz e de boa fonte; pela liderança; pela rápida e correta leitura de jogo; por entusiasmante comunicação, que motive os jogadores; e por admirável sabedoria de vida. [...] O treinador ideal será aquele que irradia prestígio de longa existência de vitórias, na modalidade desportiva onde trabalha, de grande dignidade nas horas mais e menos felizes e de um querer inflexível, coroado por um grande humanismo, em todos os momentos (SÉRGIO, 2013, p. 67).

Num treino de dominância física, o jogador de futebol (o atleta) é um ser de sentimentos. E se ele se encontra incompatibilizado com o treinador?... E, se nesse dia o pai está gravemente doente?... E se um dos filhos ficou em casa, com febre alta?... É evidente que, assim, o treino se transforma num espaço de insanável aborrecimento e, nalguns casos, de aversão.

Sublinhando as palavras de António Damásio à revista do Expresso: 
Os humanos não têm apenas a inteligência, têm por exemplo a linguagem. E temos uma socialidade muito mais complexa do que a de outras criaturas. E os impulsos criativos. E, analisando estas respostas, vemos a ideia. A ideia forte é a de que tudo o que há de bom e de bem, tudo o que ajudou instrumentalmente a criar culturas nunca teria acontecido se não tivéssemos sentimentos. Sentimentos, ora de dor e sofrimento, ora de plenitude e prazer (ALVES, 2017).

O que é peculiar no jogador, por ser gente, é secundário e acaba por reduzir-se às necessidades primárias da tática, nos "estudos" de alguns pseudo-especialistas. Não, não é que a tática não seja importante, mas, antes da tática, está o ser humano-jogador.

Da complexidade humana emerge o mundo físico, o mundo químico, o mundo vivo e, ao mesmo tempo, estamos separados deles, pelo nosso pensamento, a nossa consciência, a nossa cultura. [...] no ser humano, há o quantitativo e o qualitativo e o nosso duplo enraizamento deve ser observado, investigado, estudado, no Desporto e não é só. [...] o Desporto não é apenas uma Atividade Física, é verdadeiramente uma Atividade Humana. [...] Como desporto que é, o futebol é também uma Atividade Humana. Por isso, quem sabe só de futebol ainda não sabe de futebol. [...] No caso do desporto de alto rendimento, tendo em vista uma cada vez maior capacidade de trabalhar em equipa e desenvolvendo, para além dos conhecimentos tecnocientíficos, uma sabedoria que se manifesta: na simpatia e compreensão pelas pessoas; na aceitação fraterna das diferentes opiniões; na consciência de que muito se pode aprender com os outros (SÉRGIO, 2013, p. 59-60).

Só é possível esperar respostas humanas dos jogadores, se forem respeitados (e estudados) como humanos.

Do jornal I (Lisboa), de 9 de Maio de 2009 [...] “"Estou todo dolorido. Domingo não consigo mexer-me' é um dos comentários recorrentes do balneário do Benfica. Alguns jogadores questionam os métodos do preparador físico Paco Ayestaran e garantem que o cansaço nos jogos se deve ao excesso de exercícios no ginásio". Como se o fundamental, no treino, fosse a dimensão física. $O$ fundamental, no treino, é a complexidade humana. Como sabem pouco os que têm mais poder do que sabedoria, mais arrogância do que humildade, mais retórica do que reflexão! Como sabem pouco de futebol os que só sabem de futebol! (SÉRGIO, 2012, p. 173).

"Há hoje, uma nova visão do Cosmos, um novo Logos, um novo Método, um Mundo profuso, sugestivo e provocante. Por que não um novo futebol onde se saliente sua dimensão lúdica?” (SÉRGIO, 2012, p. 173), onde se considere quatro importantes planos:

Plano antropológico e tático: competências de ordem global, que permitem a definição de um jogador de futebol, com autor da realidade e não como mero sujeito passivo, ao sabor das circunstâncias de cada momento. Aqui também se realça a importância dos valores morais e políticos que devem nortear as instituições desportivas. Plano cognitivo: capacidade para analisar e interpretar as várias situações, a caosalidade e a causalidade, em que o futebol se desdobra. Plano da motivação: ou da vivência dos valores que justificam o não dar menos que tudo, em defesa dos objetivos propostos. Plano de relacionamento interpessoal, onde eu, sem deixar de atender à especificidade do meu lugar na equipa, sou um de nós! (SÉRGIO, 2013, p. 87). 
E na trajetória para a transformação do futebol, o desporto escolar e o desporto popular podem assumir uma posição fundamental:

E o desporto escolar? E o desporto popular? Podem ser eles o contra-poder que se anseiam? Podem ser ou podem não ser! Porque há uma unidade concreta em todos os sistemas sociais, entre o material e o formal e, portanto, os agentes desportivos, mesmo os bem-intencionados, vêem, imediatamente, o desporto, dentro de um processo material objectivo. [...] O desporto escolar (como o desporto popular) não se compreende um em si. Ele está, no mesmo todo, como uma das partes, ao lado doutras e na consciência dos desportistas, é no todo que se reflecte e projecta. No entanto, a uma correcta compreensão desta problemática, não há totalidade sem contradições e o desporto escolar e o desporto popular podem constituir dois elementos imprescindíveis às transformações da realidade desportiva (SÉRGIO, 1999, p. 261-262).

Como bem lembra Kunz (2006, p. 124): “[...] assim como o esporte se configura, enquanto realidade socialmente construída com a finalidade única de atender ao princípio do rendimento esportivo, não pode ser aproveitado pedagogicamente sem trazer prejuízos na formação de pessoas críticas e emancipadas”.

Em síntese, gostaria de apresentar [...] os pontos mais contravertidos do esporte para uma prática educacional na formação da cidadania crítica e emancipada: 1. O esporte como é conhecido na sua prática hegemônica, nas competições esportivas e nos meios de comunicação [...], não apresenta elementos de formação geral - nem mesmo para a saúde física, mais preconizado para essa prática - para se construir uma realidade educacional. 2. O esporte ensinado nas escolas enquanto cópia irrefletida do esporte de competição ou de rendimento, só pode fomentar vivências de sucesso para a minoria e o fracasso ou a vivência de insucesso para a maioria. 3. Esse fomento de vivências de insucesso ou fracasso, para crianças e jovens em um contexto escolar é, no mínimo, uma irresponsabilidade pedagógica por parte de um profissional formado para ser professor. 4. O esporte de rendimento segue os princípios básicos da "sobrepujança" e das "comparações objetivas", os quais permanecem inalterados mesmo para os esportes praticados na escola onde por falta de condições ideais o rendimento não se constitui no objetivo maior da aula. Este é um dos motivos que contribui para que o ensino dos esportes, também, venha a influenciar as crescentes "perda de liberdade" e "perda da sensibilidade" do ser humano, pelo "racionalismo" técnico-instrumental das sociedades industriais modernas (KUNZ, 2006, p. $125)$.

Complementa Kunz (2006, p. 124), lançando duas interrogações: "Mas, quem disse que o esporte para participar do conteúdo pedagógico [...] precisa necessariamente copiar de forma irrefletida e direta o modelo do esporte de competição ou de rendimento?"; "Não seria possível desenvolver uma concepção de esporte para o ensino escolar onde o mesmo passasse por um processo de transformação e assim poder atender ao compromisso de responsabilidade formativa que se deseja?".

Só assim podemos compreender o futebol...

Não há dúvida: o futebol é o fenómeno cultural de maior magia no mundo contemporâneo! Por isso, o futebol (e o desporto) não é para mim uma Atividade Física tão-só. Para que sintamos nele um humanismo fraterno, salubre e autêntico; e, porque nos encontramos no âmbito das ciências hermenêutico-humanas - que saibamos estabelecer uma analogia entre análise de textos e análise das ações. Uma ação é sempre um texto e um contexto, que se podem ler e compreender. Assim como a autonomia semântica de um 
texto não pode isolar-se, nem do "evento linguístico", nem da intencionalidade do autor, também o comportamento de um jogador, em campo, tem uma significação e um sentido, que é preciso saber descobrir. Por outras palavras: no futebol, é preciso ouvir o não dito e ler o não escrito (SÉRGIO, 2013, p. 93-94).

...a partir de rupturas e nas ciências humanas! 


\section{REFERÊNCIAS}

ALVES, C. F. A vida dos sentimentos. Expresso (Portugal), Sociedade, 05 nov. 2017.

DRUCKER, P. F. Sociedade pós-capitalista. Lisboa: Actual Editora, 2003.

JAPIASSU, H. Nascimento e morte das ciências humanas. Rio de Janeiro: Francisco Alves, 1978.

KUNZ, E. Transformação didático-pedagógica do esporte. 7. ed. Ijuí: Editora Unijuí, 2006.

LA METTRIE, J. O. O homem máquina. Lisboa: Editorial Estampa, 1982.

PORTUGAL. Proposta de lei, de 25 de Fevereiro de 1939, apresentada pelo Ministro da Educação Nacional, Carneiro Pacheco, à Assembleia Nacional. Boletim de Documentação e Informação, v. 1, n. 1, jan.-mar. 1972.

SÉRGIO, M. As lições do professor Manuel Sérgio: motricidade humana e futebol. Lisboa: Prime Books, 2013.

SÉRGIO, M. Filosofia do futebol. 4. ed. Lisboa: Prime Books, 2012.

SÉRGIO, M. Um corte epistemológico: da educação física à motricidade humana. Lisboa: Instituto Piaget, 1999.

SÉRGIO, M. Educação física ou ciência da motricidade humana? 2. ed. Campinas: Papirus, 1991.

Recebido em: 23 dez. 2018.

Aprovado em: 14 fev. 2019. 